\title{
Correction: A Feasible and Efficacious Mobile-Phone Based Lifestyle Intervention for Filipino Americans with Type 2 Diabetes: Randomized Controlled Trial
}

Melinda S Bender ${ }^{{ }^{*}}$, PhD, RN, PNP-BC; Bruce A Cooper ${ }^{2 *}$, PhD; Linda G Park ${ }^{3 *}$, PhD, RN, FNP-BC, FAHA; Sara Padash $^{4 *}, \mathrm{BS}$; Shoshana Arai ${ }^{1^{*}}, \mathrm{PhD}, \mathrm{RN}$

\footnotetext{
${ }^{1}$ Family Health Care Nursing Department, School of Nursing, University of California San Francisco, San Francisco, CA, United States

${ }^{2}$ Office of the Dean and Administration, School of Nursing, University of California San Francisco, San Francisco, CA, United States

${ }^{3}$ Community Health Services, School of Nursing, University of California San Francisco, San Francisco, CA, United States

${ }^{4}$ School of Nursing, University of San Francisco, San Francisco, CA, United States

*all authors contributed equally
}

\section{Corresponding Author:}

Melinda S Bender, PhD, RN, PNP-BC

Family Health Care Nursing Department

School of Nursing

University of California San Francisco

2 Koret Way, N431C, Box 0606

San Francisco, CA, 94143

United States

Phone: 14155025668

Email: $\underline{\text { melinda.bender@ucsf.edu }}$

\section{Related Article:}

Correction of: http://diabetes.jmir.org/2017/2/e30/

(JMIR Diabetes 2018;3(4):e12784) doi: 10.2196/12784

The authors of the paper "A Feasible and Efficacious Mobile-Phone Based Lifestyle Intervention for Filipino Americans with Type 2 Diabetes: Randomized Controlled Trial" (JMIR Diabetes 2017;2(2)e30) made a mistake in the final stage of proofreading. The metadata incorrectly designated Linda $G$ Park as a PNP instead of a PhD. Her correct designation is $\mathrm{PhD}$, RN, FNP-BC, FAHA.
The correction will appear in the online version of the paper on the JMIR website on December 21, 2018, together with the publication of this correction notice. Because this was made after submission to PubMed, PubMed Central, and other full-text repositories, the corrected article also has been resubmitted to those repositories.

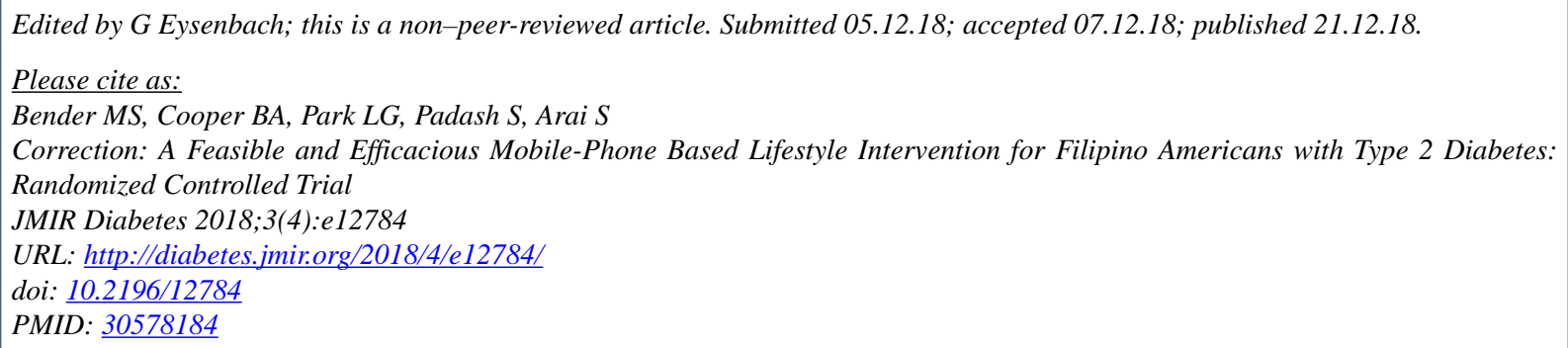

CMelinda S Bender, Bruce A Cooper, Linda G Park, Sara Padash, Shoshana Arai. Originally published in JMIR Diabetes (http://diabetes.jmir.org), 21.12.2018. This is an open-access article distributed under the terms of the Creative Commons Attribution License (https://creativecommons.org/licenses/by/4.0/), which permits unrestricted use, distribution, and reproduction in any medium, provided the original work, first published in JMIR Diabetes, is properly cited. The complete bibliographic 
information, a link to the original publication on http://diabetes.jmir.org/, as well as this copyright and license information must be included. 